\title{
Clinical judgment and best evidence: will I be sued if I do not follow the guidelines?
}

\author{
Tarun K Sharma' \\ Stephen A Vernon² \\ 'Worcestershire Acute Hospitals \\ NHS Trust, ${ }^{2}$ University Hospital, \\ Nottingham, UK
}

This article was published in the following Dove Press journal:

Clinical Optometry

26 July 2012

Number of times this article has been viewed
Correspondence: Stephen A Vernon Department of Ophthalmology, University Hospital, Nottingham NG7 $2 \mathrm{UH}$, United Kingdom

Tel +44 II 9249924 extn 63200

Email stephen.vernon@nuh.nhs.uk

\begin{abstract}
Optometrists are increasing their roles into the field of clinical management. Making management decisions and treating patients increases the risk of litigation. Guidelines have been developed to assist in the clinical care of patients and are being increasingly used in litigation cases to assist in the decision making process. This article outlines the status of litigation as it relates to current optometric and ophthalmic practice, and discusses clinical management in the context of guidelines. In some countries, including the UK, optometrists are becoming the principal providers of primary eye care in the community, with their role expanding beyond traditional refractive practice into the realm of the treatment of medical conditions. The delivery of health care in the modern era is becoming increasingly challenging as a result of improving patient knowledge via the Internet, and a commensurate rise in patient expectations. In addition, close scrutiny by the media and those in the legal profession has appeared to drive an increase in claims against practitioners. Practitioners are vulnerable to litigation when patients consider that their care has fallen below acceptable standards. This article discusses the current status of guidelines with respect to potential litigation in the context of clinical care as it relates to expanding roles within optometric practice.
\end{abstract}

Keywords: guidelines, litigation, optometrists

\section{Basic legal liability concepts: litigation}

Litigation is the process by which individuals access their legal right to recourse following suspected malpractice or negligence by a provider of a service. The provider may be an individual or an organization, and either or both may be the subject of a claim. Claims lead to the prospect of compensation, which is usually in the form of financial recompense. In order to substantiate a claim, the claimant, most commonly via his or her legal representatives, is required to either come to an agreement with the accused that recompense is in order, or take the claim to court. The accused practitioner or organization will usually be represented by his or her defensive legal team, especially should the claim be likely to come to court. The "sine qua non" for a successful claim in relation to an episode of medical or paramedical practice is proof of negligence by the individual service provider or organization. In addition, harm must have resulted as a direct consequence of the negligence. "Harm" can take many forms, ranging from psychological distress or physical injury to the claimant and his/her family to projected loss of future income for the claimant.

\section{Basic legal liability concepts: negligence and standard of care}

A "tort" is defined as a civil wrong for which a remedy may be obtained, usually in the form of damages. ${ }^{1}$ The most common form of malpractice action against a health 
care provider is the tort of "negligence." The plaintiff's legal team must prove four elements to be successful in a medical malpractice lawsuit:

a. that the provider has an obligation (duty) of care for the individual;

b. that the duty was violated (breach) by practice below the accepted standard of care;

c. that the substandard practice caused the harm alleged (proximate cause); and

d. that the plaintiff suffers compensable harm (damages). ${ }^{2}$ The health care professional's duty is defined by the legal standard of care. It is essential that a health care professional exercise the degree of care that would be expected from a similar professional of good standing in the same specialty in like circumstances. ${ }^{3}$ Establishing that the health care professional has failed to provide an acceptable standard of care is often the most critical element of the lawsuit. Expert witness testimony is usually required to establish the standard of care that applied when the alleged negligence took place. Respected clinical guidelines have, with increasing frequency, become a key element used to establish the current standard of care. ${ }^{4,5}$

\section{Negligence and litigation in ophthalmic practice}

Even if all adverse events, however defined, could be avoided, not all of the costs of malpractice litigation would be eliminated. In the USA, The Harvard Medical Practice Study ${ }^{6,7}$ found that while less than $2 \%$ of negligent injuries led to claims, over $80 \%$ of negligence claims were brought in cases in which there was no injury and no negligence. ${ }^{8}$

From the figures from the Medical Defence Union ${ }^{9}$ (a major UK medical malpractice insurance organization), patients received compensation as a result of negligence in the following ophthalmic clinical circumstances:

a. cataract treatment, 39\%

b. laser treatment, $34 \%$

c. detached retina, $7 \%$

d. glaucoma, $6 \%$

e. nonophthalmic medical condition (for example, cerebral tumor or hypertension), $6 \%$

f. blepharoplasty, $3 \%$

g. others, $5 \% 9$

Within the cataract group, the majority of claims in the UK relate to complications of surgery, with the major reasons for successful litigation being poor consent procedure and inadequate contemporaneous documentation of complications. ${ }^{10}$
Ophthalmology ranks around mid-range amongst all medical or surgical branches in terms of the likelihood of litigation activity. Data from the United States (Physician Insurance Association of America [PIAA], an association of over 50 medical malpractice insurance companies that, between them, insure over $60 \%$ of private practitioners in the USA) reported that of the 28 specialty groups included in the database, ophthalmology ranked 10th in the number of closed and paid claims reported, based on US data from 1985-2005. ${ }^{11}$

The average level of damages awarded is much higher in the USA (PIAA mean $=\$ 174,000$ versus UK National Health Service Litigation Authority $($ NHSLA) mean $=£ 37,100) .{ }^{11-13}$ The proportion of claims resulting in payment (the paid to closed ratio), however, is higher in England (NHSLA 46\%; PIAA 29\%).

Key factors leading to settlement in ophthalmic clinical circumstances other than cataract treatment included failure or delay in diagnosis or treatment, technical issues such as incorrect setting of lasers, prescribing errors, inadequate consent, and postoperative infection. ${ }^{13,14}$

Many optometrists are involved in glaucoma care in the UK, ${ }^{15}$ which is of note in the current discussion as glaucoma-related claims and lawsuits are more likely to result in indemnity payments, and those payments are likely to be substantially larger than those of other types of ophthalmic claims. Craven reported that half of all glaucoma-related claims result in an indemnity payment, and these payments are almost 20\% higher than the average ophthalmology indemnity payment. ${ }^{13}$ Data from the NHSLA show that the paid to closed ratio is $64 \%$ in glaucoma cases in the UK, much higher than in the USA (42\%, according to PIAA). ${ }^{11}$ The average level of damages paid in the UK was $£ 77,000$, with a range of $£ 5,000$ to $£ 715,000$. ${ }^{12,13,16}$

\section{Protection against litigation}

In the UK, medical practitioners and optometrists who work solely within hospital NHS will be practicing under the "Crown Indemnity" scheme, and should be covered by their employing Trust in the case of individual or institutional negligence. For all other practice, including "high street" optometric activity, separate indemnity insurance is necessary to protect the practitioner from personal liability in a proven case of negligence.

Professional indemnity insurance is a form of liability insurance that helps protect professional advice and serviceproviding individuals and companies from bearing the full cost of defending against a negligence claim made by a client, and damages awarded in such a lawsuit. The coverage focuses on alleged failure to perform on the part of, financial 
loss caused by, and error or omission in the service provided by or product sold by the policyholder. Professional liability insurance may take on different forms and names depending on the profession. For example, when relating to the medical profession it is called malpractice insurance, while errors and omissions (E\&O) insurance is used by business consultants, brokers and lawyers.

In the UK, the majority of optometrists are protected by Professional Defence and Insurance cover from the Association of Optometrists (AOP). This cover is slightly different from the cover provided to doctors by their medical defense organizations. AOP cover is "claim-made" based, while cover for doctors is usually "occurrence" based. The AOP will only cover a practitioner if they are a current member or if they have taken out additional cover for retirement or a career break. Cover for a doctor is usually valid if, at the time of alleged harm to a patient, a policy existed, irrespective of the membership status at the time of the claim. The AOP website clearly explains the nature of the indemnity cover it provides and the conditions to be applied. Optometrists are advised to take the advice of the AOP's experienced legal team regarding indemnity insurance and its validity if they plan to do extra clinical work outside the usual boundaries of optometric care. This is particularly relevant if they are utilizing new qualifications that permit prescribing or caring for specific medical conditions.

\section{Optometrists and litigation risk}

As optometrists take up new roles in the delivery of eye care (such as postoperative cataract care and involvement in various models of glaucoma care), it is extremely important to appreciate the litigation environment in the world of ophthalmic care.

An optometrist in his/her practice is directly responsible for and thus exposed to a mixture of administrative and clinical issues. Ideally, a practitioner should carry out a full risk assessment of all aspects of his/her activities to reduce the risk of complaints and litigation. The AOP gives clear guidance on risk management in optometric practice. The main areas of concern are defined in Table 1. A detailed discussion on each of these issues is not possible in this article and readers are advised to refer to the AOP's clear directions on the subject.

\section{Optometrists and the "limitation period"}

An important factor in litigation claims is the "limitation period," which is the maximum time permitted between
Table I Important areas resulting in litigation against optometrists

Patient confidentiality

Loss of computer data

Incorrect spectacle and contact lens prescriptions

Keeping full clinical records

Safety of patients on premises

Submission of claims

Keeping up-to-date clinically

Missed pathology

Misdiagnosis

the alleged negligence and the official registering of the claim. The medicolegal view concerning the limitation period published on the AOP website may, however, need amendment.

The limitation period for bringing claims for clinical negligence is three years from the date that the patient knew or should have known that his injuries were significant and had resulted from an act or omission of an identifiable professional. ${ }^{17}$

Although the AOP goes on to outline that there may be exceptions to the rule, the example given is related to children, and we suggest that this view may not be valid for those optometrists who are providing enhanced eye care services such as postoperative cataract care or glaucoma care. In NHS litigation cases, the average time to notify a claim was 2.5 years but was up to 7 years. ${ }^{18}$ According to the Medical Protection Society (an organization similar to the Medical Defence Union), there was a claim brought 23 years after an incident but the average period was 36 months (Dr S Bown, Director of Education \& Communications, Medical Protection Society, email communication, 13 June, 2007).

\section{Why might a claim be successful?}

The following are examples within categories of claim to illustrate the mechanisms that may lead to a claim being substantiated:

1. Failure to diagnose: ${ }^{16}$ A claimant had been examined on a regular basis for many years and a failure to diagnose glaucoma led to a delay in treatment and consequential loss of sight. The total damages in this case were $£ 620,035$. $^{16}$

2. Complication of tonometry: A patient suffered pain and blurring due to use of a tonometer from which disinfectant fluid had not been removed prior to use. A total of $£ 5000$ was paid in damages. ${ }^{16}$

3. Delay in follow-up: The patient attended a hospital with blurred vision. He was scheduled to be reviewed after some months but a follow-up appointment was not given, 
and the patient later attended with advanced glaucoma. The patient alleged negligent failure of follow up arrangements by the hospital, and was awarded $£ 87,178$. ${ }^{16}$

4. Failure to diagnose second pathology:20 A 32-year-old patient with diabetes presented for the first time with a complaint of right eye irritation for three days. The patient's acuity was 6/6 (20/20) in each eye, and the optometrist had found a staining corneal defect temporal to the visual axis, along with cells and flare in the right eye only. He diagnosed keratouveitis and treated the patient with topical steroids, antibiotic and dilating drops. The patient was later diagnosed to have proliferative diabetic retinopathy and rubeotic glaucoma with an IOP of $70 \mathrm{mmHg}$ by another health care professional. On reviewing the records, it was found that the optometrist had not documented the IOP or the findings of the dilated fundus examination, although there was documentary evidence that the pupils had been dilated. The final settlement sum was undisclosed in this case. ${ }^{19}$

5. Missing nonophthalmic pathology: A 13-year-old girl presented to an optometrist with reduced vision in the right eye with a family history of amblyopia. The optometrist found a best-corrected vision of 6/18 (20/60) with $\mathrm{a}-0.25$ sphere, normal pupils, fundus examination, and confrontation visual fields. The optometrist reassured the patient and parents that the cause of the reduced acuity was mild amblyopia. A year later, the patient presented with a sudden further decrease in vision. An ophthalmologist then diagnosed a large brain tumor anterior and superior to the optic chiasm as the cause of the visual loss. After informed consent, neurosurgery was performed but the patient subsequently lost vision in both eyes. The only practitioner sued was the optometrist for the substandard care provided on the first visit, with a jury trial revealing that the patient had been recorded with normal acuity in both eyes on three previous school screening sessions. The final settlement sum was undisclosed in this case. ${ }^{20}$ The cases above emphasize the importance of having a high index of suspicion, carrying out an appropriate examination, documenting the findings, and taking the appropriate action. ${ }^{19}$

The following case history provides the opportunity to analyze a few critical learning points:

Mrs V, a 49-year-old music teacher, was referred to an ophthalmologist, Mr S, following a letter from her optometrist to her general practitioner (GP). The optometrist had suspected glaucoma following a finding of right optic disc cupping in association with a disc hemorrhage, slightly raised intraocular pressures, but normal visual fields. Mr S reassured the patient that, as there was a normal visual field in the right eye, there were no signs indicating glaucoma in the eye at that time. Mrs $\mathrm{V}$ was reviewed regularly by $\mathrm{Mr}$ S, who documented a deterioration in acuity but did not give a cause in his notes or in letters to the GP over a 4-year period. Documented evidence included intraocular pressure measurements, optic disc assessments, and a number of investigations including serial automated visual field tests. Mrs V expressed concern about the progressive deterioration in her vision. Her maternal grandmother had gone blind from glaucoma and her mother was receiving glaucoma treatment. Mr S did not offer Mrs V an explanation for the progressive deterioration in her sight or offer a referral for a second opinion. Mrs $\mathrm{V}$ then relocated to a new town for personal reasons and was seen by a different ophthalmologist who found abnormalities consistent with advanced glaucoma in both eyes and significant visual field loss. Mrs V was registered partially sighted and lost her driving license. She underwent rehabilitation at work but was unable to work without the use of low vision aids.

Mrs V subsequently made a claim against $\mathrm{Mr} \mathrm{S}$. The case notes submitted by $\mathrm{Mr} \mathrm{S}$ reported normal examinations, which included recordings of normal pressures and normal optic disc appearance. However, during the investigation of the case, it was proved that clinical notes were rewritten after the event by Mr S. It was later found that the original notes recorded the finding of physiological disc-cupping, but $\mathrm{Mr} \mathrm{S}$ had failed to record cup-disc ratios, which could have helped in monitoring deterioration in the health of the discs and ultimately to diagnose Mrs V's glaucoma. It was obvious that the rewritten clinical notes were an attempt to disguise the original failure to diagnose.

Expert opinion concluded that Mrs V was always at risk of glaucoma and that she should have been carefully monitored with detailed reporting of the state of the optic discs. In addition, it was deemed by the expert witnesses that the patient would, on the balance of probabilities, have had signs consistent with glaucoma when she had first attended Mr S's clinic. Treatment for glaucoma or a referral to a glaucoma specialist for further care should have been offered. The case was settled for a high sum, reflecting the permanent and severe nature of the damage to vision.

There are several learning points in this case history:

1. The UK's General Medical Council guidance on good medical practice states that, in providing care, the medical professional must "keep clear, accurate and legible records, reporting the relevant clinical findings, 
the decisions made, the information given to patients, and any drugs prescribed or other investigation or treatment." ${ }^{20}$ It is likely that this standard of practice would also apply to optometrists working in a similar role.

2. Practitioners who fail to make the care of the patient their primary concern put themselves at risk of both disciplinary action and medicolegal claims.

3. Medical notes have to be considered not only as medical documents but as legal documents.

4. Passing off rewritten records as contemporaneous is a criminal offence and any retrospective change has to be clearly marked, dated, and signed, with the reason for the change also documented. Altering existing medical records, removing records, or adding false records puts a doctor/optometrist at high risk of referral to their regulatory body on the grounds of poor probity. Disclosure of authentic, original clinical notes is essential when a claim is brought. Failure to do so can make a claim indefensible.

5. Early glaucoma is, unfortunately, a diagnosis that can be easily missed. The Royal College of Ophthalmologists, the National Institute of Clinical Excellence (NICE), and the European Glaucoma Society provide easily accessible and up-to-date guidelines on the diagnosis and management of glaucoma that practitioners should be familiar with. ${ }^{21}$

6. All health professionals are responsible for keeping upto-date, should know their limitations, and should work with colleagues to provide the best level of care for their patients.

7. Listening to the patient and responding to their concerns is vital, not just for the purpose of making an accurate diagnosis, but also for the establishment of rapport and trust.

8. Practitioners should be prepared to reconsider a diagnosis that was eliminated on an earlier visit by having an open, unbiased mind at each consultation.

9. Practitioners should consider getting a second opinion if they are unable to account for a patient's symptoms or clinical signs.

\section{Clinical guidelines and their incorporation into the health care/litigation scenario}

Since the early 1990s, many professional ophthalmic bodies have produced clinical guidelines, with some undergoing multiple revisions over subsequent years. In the last few decades there has been growing emphasis on evidence-based medicine and this has contributed to an increase in the prevalence of formal clinical guidelines.
Guidelines aim to narrow the gap between ideal care and actual care. A particularly good definition and explanation of the term "clinical guidelines" has been published by The College of Physicians and Surgeons of Ontario, who state: "Clinical guidelines are systematically developed and updated, evidence-based or consensus-based statements whose purpose is to help improve the quality and consistency of care in specified clinical situations." ${ }^{22}$

In explaining their statement, the college develops the theme, indicating that guidelines are developed to promote best practice for populations of patients and will therefore have variable applicability to individual patients. In addition, they remind us that guidelines are not inflexible protocols and should not replace professional judgment. ${ }^{22}$ The importance of this principle is evident in a statement included in the UK NICE guidelines for the management of glaucoma and ocular hypertension, which indicates that the guidelines are intended to provide recommendations that will apply to $80 \%$ of clinical situations on $80 \%$ of occasions. ${ }^{23}$ This acknowledges that individual cases require individual management decisions, and encourages the health care professional to provide appropriate care that will change according to the circumstances.

Guidelines may go out of date rapidly (and some do not have review dates) as new scientific evidence is published, and following an out-of-date guideline will not always be consistent with best or even acceptable practice.

In the UK, guidelines from NICE dominate the clinical practice environment and the optometrist must be familiar with them. In addition, useful guidance has been published jointly by the Royal College of Ophthalmologists and the College of Optometrists. ${ }^{24}$ It is wise also to be aware of guidance from other organizations that relate to relevant practice, as some scenarios may not be covered in a NICE guideline.

Guideline quality may be assessed formally using analysis tools. ${ }^{25}$ There is good evidence that clinical guidelines can improve patient management, with a review of 59 studies that evaluated the effect of clinical guidelines on patient care detecting significant improvement in the process of care in all but four of the studies. ${ }^{25}$ Despite the widespread recognition of the potential value of the use of clinical guidelines in health care improvement, their legal status has been unclear and this is of growing concern to some health care professionals.

\section{Are clinical guidelines necessary?}

Guidelines have been shown to improve care in a number of medical conditions, and they can assist practitioners as well as patients. ${ }^{25}$ As medicine has become more litigious, 
defensive medicine patterns are becoming more widespread. Defensive medicine can be considered to be the ordering of tests and investigations and the delivery of treatments that help protect the doctor rather than further the patient's care. A survey revealed that $70 \%$ of professionals identified media criticism of health professionals as a contributing factor to them practicing defensively. ${ }^{26}$ The personal impact of litigation, such as the value of lost time, emotional energy, and reputational damage, is often perceived to be more costly than the cost of taking precautions. ${ }^{26}$ Doctors and other health care professionals may practice defensively partly through a fear of being sued, and such activity has been linked to poor clinical knowledge or lack of experience.

Defensive medicine should not, however, be confused with defensible practice, which is synonymous with good medical practice.

\section{Guidelines and the law}

There is a lack of clarity about how clinical guidelines may be used in a legal setting. In particular, there is uncertainty about whether health care professionals will be more, or less, vulnerable to a successful lawsuit if they follow or depart from guidelines, even when there are sound clinical reasons. There is usually a significant time lag before malpractice cases come to court, and litigation currently before court often relates to incidents that occurred several years before the publication of a relevant guideline.

In order to predict whether a practitioner is at risk of successful litigation if a well-accepted guideline is not followed, a value judgment has to be made based on knowledge of the common causes for litigation, an understanding of the principles of clinical negligence law, a history of similar cases that came to court or were settled, and the judgments delivered. Similarly, analyses of all cases managed by defense associations within a subspecialty area, whether they came to court or not, will supply a framework on which to base a risk management strategy to prevent litigation in one's practice. ${ }^{10}$

\section{The approach of the English courts to guidelines}

In a clinical negligence claim, the courts use the Bolam principle to establish whether a doctor has acted in accordance with a "responsible body of reasonable medical opinion."27 In 1997, the Bolitho test ${ }^{28}$ modified the Bolam test. The Bolitho test requires the health care professional who was allegedly negligent to be found to have been unreasonable. If the professional is acting in accordance with a responsible body of medical opinion (Bolam) and those decisions stand up to logical analysis and scrutiny (Bolitho), then the claim is very unlikely to succeed. If a professional takes the time and trouble to explain to the patient the reason for the decision in the first place, and documents the fact that the discussion has taken place, it would appear likely that the chance of the patient bringing a successful claim will be significantly reduced.

English courts do not accept guidelines as evidence of responsible or proper practice without taking expert evidence. As the senior author of a guideline is not normally available to give oral testimony, such evidence is classed as hearsay, and other experts will be appointed. They will interpret the case taking into account any relevant published literature and their own clinical expertise and experience. Guidelines may differ in their advice, further muddying the waters, but significant deviation from a guideline produced by a respected academic group in the country of practice (such as the Joint Royal College of Ophthalmologists and College of Optometrists guidance documents) is likely to be taken seriously by the courts.

It is possible that NICE guidelines will form a new "normative" framework, providing evidence of the standard of care to which health care professionals ought to conform. Indeed, many commissioners of care have amended employment contracts to state that staff should follow NICE guidelines. Thus, adhering to NICE guidelines may provide the evidence to sustain a Bolam defence, and it may be becoming increasingly difficult for a health care professional to defend a deviation from NICE guidelines, as a court may refuse to regard the deviation as "logically defensible." 28

This suggests that while a claimant will still need to satisfy the burden of proof, a court is likely to be sympathetic when a patient suffers harm as the result of a departure from a well-established guideline, particularly when the reasons for variance have not been recorded. Health care professionals are therefore advised to carefully record their reasons for deviating from guidelines, and be aware that a deviation may be difficult to defend.

\section{Is the frequency of litigation in optometry increasing?}

Litigation appears to be more common in the USA compared with the UK. It is therefore encouraging that a recent report documenting the outcome of cases against optometrists in the USA, many of whom are more active in "medical" case management than has been traditional in the UK, has indicated that the frequency of and payout in successful litigation 
has not increased in the last two decades, with an average of only 34 cases per annum being recorded. ${ }^{29}$ However, if an increase in claims is to be avoided as optometrists take on increased responsibility for ophthalmic care, they will need to be wary of the pitfalls of medical practice, as illustrated in this article.

\section{Conclusion}

All health care professionals have an ethical obligation to keep up-to-date throughout their careers, and this includes a requirement to be aware of the latest guidelines and the best evidence. Guidelines do not and should not imply that health care professionals must suspend their clinical judgment in order to follow them to the letter, and this has been emphasized in the NICE glaucoma guidelines. However, good documentation of a comprehensive and relevant consultation including a two-way discussion with the patient is essential when deviating from a widely accepted guideline. Such action should satisfy all ethical and legal principles, and should keep a practitioner and his/her patient at low risk of being involved in litigation at a later date.

\section{Disclosure}

The authors declare no conflicts of interest in this work.

\section{References}

1. Garner BA, editor. Black's Law Dictionary, 8th ed. New York: Thomson Reuters; 2004.

2. Richards EP, Rathbun KC. Medical Care Law. Gaithersburg: Aspen Publishers; 1999.

3. Mello MM. Of swords and shields: the use of clinical practice guidelines in medical malpractice litigation. Univ Penn Law Rev. 2001;149: 645-710.

4. McConkey SA. Simplifying the law in medical malpractice: the use of practice guidelines as the standard of care in medical malpractice litigation. West VA Law Rev. 1995;97:491-523.

5. Ayres JD. The use and abuse of medical practice guidelines. J Legal Med. 1994;15:421-443.

6. Brennan TA, Leape LL, Laird NM, et al; Harvard Medical Practice Study 1. Incidence of adverse events and negligence in hospitalized patients. Results of the Harvard Medical Practice Study I. NEngl J Med. 1991;324(6):370-376.

7. Leape LL, Brennan TA, Laird N, et al. The nature of adverse events in hospitalized patients. Results of the Harvard Medical Practice Study II. N Engl J Med. 1991;324(6):377-384.

8. Brennan TA. Medical injuries: international perspectives. Med J Aust. $1995 ; 163(9): 475-476$.

Clinical Optometry

\section{Publish your work in this journal}

Clinical Optometry is an international, peer-reviewed, open access journal publishing original research, basic science, clinical and epidemiological studies, reviews and evaluations on clinical optometry. All aspects of patient care are addressed within the journal as well as the practice of optometry including economic and business analyses. Basic and clinical Submit your manuscript here: http://www.dovepress.com/clinical-optometry-journal
9. Tomkins C. Over 120 years of defending ophthalmologists. $\mathrm{Br} J$ Ophthalmol. 2006;90(9):1084-1085.

10. Bhan A, Dave D, Vernon SA, et al. Risk management strategies following analysis of cataract negligence claims. Eye. 2005;19:264-268.

11. PIAA (Physician Insurance Association of America). Risk management Review run date: 05/08/2006. Executive summary: page IV.

12. Ali N. A decade of clinical negligence in ophthalmology. $B M C$ Ophthalmol. 2007;7:20.

13. Van Buskirk EM. Medicolegal aspects of glaucoma care. Surv Ophthalmol. 1998:43(1):83-86.

14. Craven ER. Risk management issues in glaucoma: diagnosis and treatment. Surv Ophthalmol. 1996:40(6):459-463.

15. Vernon SA, Adair A. Shared care in glaucoma: a national study of secondary case lead schemes in England. Eye (Lond). 2010;24(2):265-269.

16. Ali MN, Fraser SG. Medicolegal aspects of glaucoma. Clin Risk. 2007;13(1):12-16.

17. aop.org.uk [homepage on the Internet]. London: AOP Association of Optometrists. Civil claims arising from allegations of clinical negligence. Available from: http://www.aop.org.uk/legal-services/ complaints/civil-claims-arising-from-allegations-of-negligenc. Accessed August 3, 2011.

18. NHS litigation authority: Fact sheet. Information on claims. 2008.

19. Sherman J. Triggers for malpractice suits. What you need to know to keep you and your patients safe. Optometric Management. Jul 2001:1-7. Available from: http://www.optometricmanagement.com/articleviewer. aspx?articleid=70183. Accessed 17 June, 2011.

20. Good Medical Practice: Providing good clinical care. General Medical Council; 2012. Available from: http://www.gmc-uk.org/guidance/ good_medical_practice/good_clinical_care_index.asp. Accessed 17 June, 2011.

21. eugs.org [homepage on the Internet]. 2011: EGS European Glaucoma Society. Terminology and Guidelines for Glaucoma, 3rd ed. Available from: http://www.eugs.org/eng/EGS_guidelines.asp. Accessed August 2, 2011.

22. cpso.on.ca [homepage on the Internet]. Toronto: The College of Physicians and Surgeons of Ontario. About clinical practice guidelines (CPG): what is a CPG? Available from: http://www.cpso.on.ca/policies/ positions/default.aspx?id=1722. Accessed August 3, 2011.

23. guidance.nice.org.uk [homepage on the Internet]. 2012: National Institute for Health and Clinical Excellence. Glaucoma: diagnosis and management of chronic open angle glaucoma and ocular tension. Available from: http://guidance.nice.org.uk/CG85. Accessed August 3, 2011.

24. college-optometrists.org [homepage on the Internet]. The College of Optometrists. Joint supplementary college guidance on supervision in relation to glaucoma-related care by optometrists. Available from: http:// www.college-optometrists.org. Accessed December 16, 2010.

25. Grimshaw JM, Russell IT. Effect of clinical guidelines on medical practice: a systematic review of rigorous evaluations. Lancet. 1993; 342(8883):1317-1321.

26. Williams S. On the defensive. Casebook. 2011;19(1):8-11.

27. Bolam v Friern Hospital Management Committee. High Court. Citations. 1957:1 WLR 582.

28. Bolitho v City and Hackney Health Authority. House of Lords. 1997:4 All ER 771.

29. Duszak RS, Duszak R Jr. Malpractice payments by optometrists: an analysis of the national practitioner databank over 18 years. Optometry. 2011;82(1):31-37.

\section{Dovepress}

research papers are published that cover all aspects of optics, refraction and its application to the theory and practice of optometry. The manuscript management system is completely online and includes a very quick and fair peer-review system, which is all easy to use. Visit http://www.dovepress. com/testimonials.php to read real quotes from published authors. 